\title{
EXPERIÊNCIA DE CONSUMO EM REALIDADES VIRTUAIS: UM ESTUDO DE CASO REALIZADO NO SECOND LIFE
}

\section{Isadora Camila Marques Soares}

Graduada em Administração pela Universidade Federal Rural do Semiárido - UFERSA

isadoracamila@hotmail.com (Brasil)

\section{Yákara Vasconcelos Pereira Leite}

Doutora em Administração pela Universidade Federal de Pernambuco - UFPE

Professora da Universidade Federal Rural do Semiárido - UFERSA

yakarav@gmail.com (Brasil)

\section{Viviane Santos Salazar}

Doutora em Administração pela Universidade Federal de Pernambuco - UFPE

Professor da Universidade Federal de Pernambuco - UFPE

viviane_salazar@yahoo.com.br(Brasil)

\section{Lílian Caporlíngua Giesta}

Doutora em Administração pela Universidade Federal do Rio Grande do Sul - UFRGS

Professor da Universidade Federal Rural do Semiárido - UFERSA

ligiesta@gmail.com (Brasil)

\section{RESUMO}

Este estudo tem como objetivo geral investigar como ocorre a experiência de consumo no Second Life. Para isso, utilizou-se um estudo de caso qualitativo. A coleta de dados foi desenvolvida por meio da observação participante, de diálogos inspirados na etnografia e entrevistas semiestruturadas. A análise de conteúdo orientou a obtenção dos resultados. Identificou-se que os sentimentos relacionados ao processo de compra são semelhantes com o que é sentido pelos respondentes ao realizarem compras na vida real e, em algumas situações, são até mais prazerosos.

Palavras-chave: Second life; Marketing; Experiência de consume; Comportamento do consumidor. 


\section{INTRODUÇÃO}

A internet se tornou parte da vida cotidiana dos indivíduos. Muitos deles fazem uso dessa ferramenta tanto para se comunicar com outras pessoas ao redor do mundo quanto para pesquisar, comparar e comprar inúmeros artigos ofertados. Esse instrumento trouxe diversas inovações às formas de comunicação (FONSECA et al., 2008).

Por volta do ano de 2004, surgiram as primeiras redes sociais, que logo ganharam destaque na internet, pois elas possibilitaram aos seus usuários a divulgação de informações pessoais e a possibilidade de fazer amigos. Em tais redes também existem fóruns de discussão sobre os mais variados assuntos, nesse local é possível conhecer pessoas novas e compartilhar opiniões com várias outras sem restrição de distância, uma vez que existem usuários ao redor de todo o mundo (SOLOMON, 2008).

Por meio da evolução dessas redes sociais e com o surgimento dos jogos de interpretação de personagens online em massa para múltiplos jogadores, ou Massive Multiplayer Online Role Playing Game (MMORPG), as empresas perceberam os novos canais de contatos com os consumidores em potencial, além de um novo meio de testar os produtos em fase de lançamento e economizar tempo e dinheiro que seriam investidos na fabricação e promoção desses produtos (THILMANY, 2008).

Um desses jogos de MMORPG bastante peculiar é o Second Life, criado pela empresa Linden Research Inc., que ao contrário da maioria dos jogos, não possui sistema de pontos, ganhador ou perdedor, ou fases que levam ao próximo nível. Como sugere o nome, neste jogo o usuário (ou residente) tem de fato uma segunda vida.

O residente pode experimentar a compra e atividades de consumo neste mundo virtual, da mesma maneira que o faz no mundo real (SHELTON, 2010) e uma das coisas intrigantes é que a maioria dos produtos ofertados é criada pelos próprios residentes, fazendo com que eles possam gerar renda por meio do programa (TERDIMAN, 2008). Por se tratar de uma realidade peculiar e “imaginária”, esse consumo experiencial vem sendo valorizado pelos seus usuários.

Para Schmitt (2000), as experiências são capazes de ligar a empresa e a marca ao estilo de vida do consumidor, criando estímulos para os sentidos e para a mente na medida em que o cliente vivencia os diversos tipos de situações os quais é submetido, de modo que as atitudes em relação ao produto e ao comportamento do consumidor na hora da compra atinjam um contexto social bem mais amplo.

Compreender a experiência de consumo neste ambiente parece ser de alta relevância, uma vez que vários autores (BONSU; DARMONY, 2008; HAENLEIN; KAPLAN, 2009; PARMENTIER;

Revista de Administração e Inovação, São Paulo, v.12, n.1, p.98-120, jan./mar. 2015. 
ROLLAND, 2009; SHELTON, 2010; TERDIMAN, 2008; THILMANY, 2008; WANDT, 2007; WOOD; SOLOMON, 2009;) destacam o crescimento tanto da quantidade de usuários, que segundo Wood e Solomon (2009) ultrapassam o número de 16 milhões, quanto do montante de recursos financeiros gasto pelos jogadores em realidades virtuais desse tipo, fazendo com que este mercado atingisse entre o segundo semestre de 2008 e o mesmo período de 2009 a marca de mais de meio bilhão de dólares em transações (LINDEN LAB, 2010). Diante disso, apresenta-se o objetivo geral do estudo: investigar como ocorre a experiência de consumo no Second Life. Para tanto, os seguintes objetivos específicos viabilizaram a investigação, quais sejam: Descrever os fatores que mais levam os usuários a empregarem recursos financeiros neste tipo de ambiente virtual; Verificar quais elementos do ambiente virtual são mais valorizados pelos jogadores entrevistados; Descobrir quais são as respostas internas dos residentes ao vivenciar uma experiência de consumo no jogo; Identificar os motivos que fazem com que os usuários permaneçam no jogo.

\section{COMPORTAMENTO DO CONSUMIDOR EM REALIDADES VIRTUAIS}

Em um mundo que possui mais de 13 milhões de avatares e multinacionais do porte da Adidas, Toyota e Vodafone, como o Second Life, os usuários são expostos a uma variedade infinita de relações sociais. Podem participar de comunidades que eles próprios criam por meio de seus avatares, o ambiente pelo qual circulam, além de colaborar em ações de lazer e/ou atividades econômicas, formando então uma comunidade de novos consumidores (PARMENTIER; ROLLAND 2009).

O Second Life é ambientado no que se chama de metaverso explicado por Kamel (2009, p. 21) como algo que:

[...] não é limitado pelo tempo e que continua a funcionar mesmo quando os jogadores não estão conectados. Navegando por horas e horas, residentes ou jogadores criam mundos paralelos para o seu mundo real. [...] Um metaverso é caracterizado por um universo e personagens que agem individualmente ou em grupos e que experimentam o universo de acordo com práticas estabelecidas pelos próprios jogadores ou residentes.

Castronova (2001) afirma que um mundo virtual é um programa de computador com três características definidoras: (i) interatividade, existe no computador e pode ser acessada remota e simultaneamente por um grande número de pessoas; (ii) fisicalidade, onde pessoas acessam o programa através de uma interface que simula um ambiente em primeira pessoa na tela do computador; e (iii) persistência, o programa continua funcinando haja pessoas usando ou não. 
Tikkanen et al. (2009) destacam que as transformações culturais e tecnológicas avançaram a emergência acelerada de novas formas de comunidade e identidade, desde as mais convencionais plataformas de rede até tipos completamente novos de realidades, como os jogos de MMORPG que se utilizam da imersão e interatividade para prender a atenção dos usuários.

As vantagens que este tipo de jogo traz para as empresas são apresentadas por Thilmany (2008) quando diz que lançando protótipos de seus novos produtos em um mundo virtual, a organização consegue como retorno uma grande economia e uma forma mais precisa de feedback dos clientes. Economia esta representada pelo baixo custo de lançamento dos protótipos online em comparação a fabricação, teste e lançamento no mundo real. Vergani e Andrade (2008, p. 2492) partilham dessa mesma ideia quando descrevem que os usuários "[...] podem ser vistos como consumidores e participantes do processo de pesquisa para desenvolvimento e implementação de novos produtos”.

No ambiente do Second Life existe ainda a possibilidade da relação de co-criação entre cliente e empresa apresentada por Bonsu e Darmondy (2008) como uma liberdade do consumidor em diversos sentidos, mas que também representa uma armadilha para que o consumidor produza para a empresa.

Em sua pesquisa Dahl e Mureau apresentam sete diferentes motivações para consumidores participarem de tarefas criativas. Vale ressaltar que há diferentes perfis de jogadores. Parmentier e Rolland (2009) destacam na sua pesquisa quatro tipos de identidade de usuários, são eles: (i) duplicação, quando o usuário tem um avatar muito próximo ao seu porte físico no mundo real e a sua personalidade real se reflete no avatar; (ii) melhoramento, o indivíduo diz que o avatar é a sua extensão, porém apenas transmite parte de si mesmo, sendo geralmente os aspectos positivos; (iii) transformação, em que o usuário rejeita no seu avatar qualquer característica que ele rejeite em si mesmo, fazendo algumas vezes de seu avatar, um oposto do que ele é na realidade; (iv) metamorfose, o indivíduo considera o avatar um ser alternativo de si mesmo, e os comportamentos e ações do avatar são totalmente imaginários.

Seguindo a linha das motivações para participar de jogos como o Second Life, Shelton (2010) cita nove delas: (i) fantasia, quando se usa o SL para fazer coisas que não se consegue fazer no mundo real; (ii) customização, para aqueles que têm interesse em modificar a aparência de um avatar; (iii) interpretação, quando se cria um residente com uma história e se interage com outras pessoas gerando assim improvisação; (iv) relacionamentos, onde a pessoa entra no SL para fazer amizades ou manter relações de longa data com outros residentes; (v) socialização, quando se usa o SL para interagir com amigos, família e conversar com outros residentes; (vi) escapismo, quando se usa o SL como uma ferramenta de escape dos problemas do mundo real; (vii) relaxamento, quando o SL é usado como 
meio de aliviar o estresse; (viii) avanço/desafio, usando o SL para aumentar o nível de habilidades e de realizações pessoais; e (ix) competição, que é o desejo de competir e desafiar outros residentes.

Hinsch e Bloch (2009, p. 49) concordam com a ideia de Shelton (2010) de que a fácil construção de relacionamentos e o escapismo são fortes motivos tanto para se fazer um primeiro login, quanto para permanecer no jogo e ainda acrescentam duas novas motivações. Poder e controle são um tipo de motivação, o fato de que o residente vive a vida que escolhe viver, criando um avatar da forma que ele imaginar e ainda possuindo uma "vida" que ele possui a liberdade de comprar produtos por ele desejados. Segurança é o outro tipo, uma vez que encontros em um mundo virtual não possuem os mesmos riscos que na vida real, pois um avatar não pode ser machucado fisicamente. Ou ainda caso o avatar seja rejeitado por outros residentes do SL, ou encontre-se em alguma situação que não o agrade ele sempre pode teleportar-se para qualquer outra locação do mundo virtual e começar tudo de novo.

No mundo real, assim como no SL, frequentemente um produto ou serviço é comprado por aquilo que representa para o consumidor ou para as pessoas com quem ele está relacionado, servindo como referência social, dando assim significado ao termo interacionismo simbólico (LEIGH; GABEL, 1992). O comportamento de compra de cada indivíduo é avaliado pelos outros membros do grupo e ainda segundo os mesmos autores podem ser divididos em três características: (i) consumidores em transição, aqueles que passam a consumir certos tipos de produtos por eles serem referência na nova situação; (ii) consumidores que ocupam alto nível de importância em um grupo social, os quais consomem de acordo com o que julgam que irá impressionar os outros membros do grupo; e (iii) consumidores que aspiram ganhar lugar em um grupo social específico, consomem aquilo que acreditam ser pré-requisito para a aceitação no grupo desejado.

Para Taurion (2009, p. 52) os residentes que surgem como líderes permanecem por meritocracia e influenciam de forma colaborativa, porém às vezes, permanecem apenas pelo cumprimento de alguma missão, ao final da qual surge uma nova liderança, encorajando assim colaborações e experimentações.

\subsection{Experiência de consumo em ambientes virtuais}

Como resposta ao desenvolvimento simultâneo nos campos da tecnologia de informação, supremacia da marca e comunicação e entretenimento no amplo ambiente de mercado houve uma mudança do tradicional marketing de "características e benefícios" para o marketing que visa criar experiências para os consumidores (SCHMITT, 1999, p. 53).

Revista de Administração e Inovação, São Paulo, v.12, n.1, p.98-120, jan./mar. 2015. 
Todas as formas de contato feitas por um consumidor a determinado produto são experiências que serão aplicadas a ele, e através da soma deste histórico é produzido o valor percebido pelo cliente. Para Flôr e Umeda (2009, p. 3), o marketing experiencial busca "oferecer produtos e campanhas que consigam estimular os sentidos e as emoções do público-alvo [...]” procurando instalar-se na memória do consumidor disseminando o sentimento que fez parte da experiência atribuída a marca.

Kamel (2009) apresenta quatro proposições de análise dos avatares para um melhor entendimento da experiência de consumo no metaverso. Afirma-se que as contribuições desta análise são significativas, porém, não dispõe de explicações sobre como os consumidores escolhem os seus avatares e a maneira como os jogadores ou residentes os envolve neste mundo. A primeira proposição sugere que no metaverso, o avatar é uma forma de expressão do auto-conceito que o consumidor escolhe em concordância com o seu ideal, real, e/ou eu social. A segunda sugestão é que o avatar é uma reflexão do papel que o consumidor escolhe para atuar no mundo virtual. A terceira suposição diz que o avatar escolhido pelo consumidor é uma reflexão das suas próprias motivações. Por último, a quarta proposição sugere que o avatar escolhido pelo consumidor seria uma reflexão dos traços da sua própria personalidade.

Quanto ao marketing experiencial, apóia-se em quatro características, que são: (i) foco na experiência do consumidor, que fornece valores sensoriais, emocionais, cognitivos, comportamentais e relacionais ao invés de valores funcionais; (ii) foco no consumo como uma experiência holística, em que o conceito de uma característica é ampliado e o significado dessa situação de consumo específico é examinado no seu mais vasto contexto sócio-cultural; (iii) consumidores são animais racionais e emocionais, que diz que os consumidores são tão emocionais quanto racionais e podem ser guiados a uma compra por puro hedonismo; e (iv) métodos e ferramentas são ecléticos, pois o marketing experiencial não está vinculado a apenas uma ideologia metodológica, mas seus métodos e ferramentas são diversos e multifacetados (SCHMITT, 1999).

Algumas características apresentadas por Schmitt (1999) encontram base em Holbrook e Hirschman (1982) que falam do fato da perspectiva experiencial suportar uma investigação mais energética de relações psicofísicas multissensoriais no comportamento do consumidor, sugerindo assim novos e diferentes métodos de interpretação, bem como do fato de que o consumo envolve um fluxo constante de fantasias, sentimentos e diversão com vários significados simbólicos, respostas hedônicas e critérios estéticos, atribuindo uma perspectiva fenomenológica e referindo-se a ele como um estado essencialmente subjetivo de consciência, ou seja, não somente feito conscientemente, mas também guiado por emoções de forma hedônica. 
Hirschman e Holbrook (1982, p. 94) explicam que o consumo hedônico tem relação com “[...] aquelas facetas do comportamento do consumidor que se relacionam com os aspectos multissensoriais, fantasiosos e emotivos da experiência com os produtos", cujos "[...] atos são baseados não no que os consumidores conhecem como real, mas naquilo que eles desejam que seja realidade".

Kamel (2009) vai além, ao fazer a conexão desse tipo de consumo experiencial com o ambiente do SL quando mostra que o metaverso oferece uma experiência hedonista ao permitir que seus residentes vivam essa sensação, uma vez que ela se encaixa nos aspectos lúdicos do consumo contemporâneo. E acrescenta que sabendo disso os editores do jogo estão despendendo esforços significantes para reforçar a convivência dos residentes e expandir as oportunidades de customização do universo virtual.

Na concepção de Okada (2005, p. 43) "as pessoas estarão mais propensas a consumir bens hedônicos quando o contexto da decisão as permite ter flexibilidade para justificar este consumo", e a diferença entre esse tipo de compra e o consumo utilitário é apenas uma questão de grau de percepção. Em seu estudo ela apresenta que uma alternativa hedônica tende a ser mais utilizada quando comparada com uma alternativa utilitária quando elas surgem isoladamente. Enquanto que a compra utilitária tende a ser escolhida com mais frequência quando as duas são apresentadas juntas. Isto ocorre porque em contrapartida a facilidade com que se justificam os gastos em bens utilitários, o consumo de bens hedônicos está sempre associado a um senso de culpa e à dificuldade de quantificar seus benefícios.

Schmitt (1999) apresenta em seu trabalho cinco Módulos Experienciais Estratégicos (MEE), que interagem entre si, dos quais as empresas podem fazer uso para criar diferentes tipos de experiência para os seus consumidores. O módulo percepção apela para os sentidos com o objetivo de criar experiências sensoriais através da visão, audição, tato, paladar e olfato. O sentir, segundo módulo apresentado, apela para os sentimentos internos com o objetivo de criar experiências afetivas que variam de estados medianamente positivos para fortes emoções de prazer e orgulho. O módulo de pensar apela ao intelecto com o propósito de criar experiências de solução de problemas que envolvem os consumidores de forma criativa. O quarto módulo é chamado de agir e enriquece a vida dos consumidores orientando suas experiências, mostrando diferentes alternativas de fazer coisas, de estilos de vida e de interações. O último modo, relacionar, contém aspectos dos outros módulos, porém vai além do indivíduo e o relaciona com algo fora do seu próprio eu, como outras pessoas e culturas.

De acordo com o tipo de MEE utilizado deve-se definir o provedor de experiência mais adequado, o qual subdivide-se em sete tipos: (i) comunicação - equivale à propaganda; (ii) identidade 
visual e verbal - nome, logotipo etc.; (iii) presença do produto - design do produto, embalagem e display de demonstração; (iv) co-branding - eventos de marketing, patrocínio, relacionamentos, licenciamentos e merchandising em filmes e campanhas cooperativas; (v) ambiente - local; (vi) web sites e mídia eletrônica; (vii) pessoas - equipe de vendas, assistência técnica, e demais pessoas vinculadas à empresa.

A estratégia de marketing que trabalha com os sentidos procura captar a atenção dos consumidores por meio de estímulos que gerem prazer estético ou excitação. As experiências sensoriais podem diferenciar empresas e produtos, além de motivar os consumidores e agregar valor.

De acordo com o estudo de Eroglu, Machleit e Davis (2001, p. 179) a atmosfera proporcionada por ambientes de lojas tradicionais, não pode ser aplicada, em sua totalidade, a ambientes de lojas virtuais, pois estas são impossibilitadas de apresentar algumas características de lojas tradicionais como a percepção do olfato, porém, apresentam peculiaridades como flexibilidade no tempo e espaço. As várias combinações do ambiente de loja real se resumem em sua maioria a apelos visuais através de um monitor.

Para Costa e Larán (2003), uma compra por impulso ocorre derivada de três fatores principais: (i) a circulação do consumidor na loja, como a atividade com fins recreativos ou informativos de percorrer e examinar o ambiente sem intenção imediata de compra; (ii) a impulsividade do indivíduo, que resulta da luta entre a vontade de comprar e o autocontrole, sendo que o desejo prevalece.; e (iii) a influência dos elementos ambientais, como a presença de cores, sons, promoções, entre outros, aumentando a permanência dos consumidores nas lojas, despertando ou gerando impulsos que levam ao ato da compra. Portanto, observa-se que há algumas diferenças entre o comportamento de compra em atmosferas tradicionais e virtuais.

\section{PROCEDIMENTOS METODOLÓGICOS}

A expressão pesquisa qualitativa assume diferentes significados no campo das ciências sociais (NEVES, 1996) e engloba técnicas interpretativas favoráveis ao delineamento e entendimento dos sentidos dos fenômenos do mundo social. Grande parte dos estudos qualitativos se realiza na fonte de origem dos dados, e os pesquisadores ao empregarem o método em questão voltam sua atenção para o processo social mais do que para a estrutura social, buscando visualizar o contexto e quando possível, integra-se com o objeto de estudo para que possa obter a compreensão do fenômeno.

Revista de Administração e Inovação, São Paulo, v.12, n.1, p.98-120, jan./mar. 2015. 
Como o tema sugerido por este estudo é pouco explorado, posto a falta de estudos nesta área, optou-se pelo uso da perspectiva qualitativa. Logo esta investigação conta com características de pesquisa exploratória a fim de "[...] levantar informações sobre um determinado objeto, delimitando assim um campo de trabalho" (SEVERINO, 2007, p. 123).

Ainda pode-se encontrar neste trabalho características de um estudo de caso, uma vez que, está restrito ao ambiente de jogo do SL. Yin (2001) aponta que o estudo de caso é uma forma de se fazer pesquisa social empírica ao se investigar um fenômeno atual dentro de um contexto de vida real, em que as fronteiras entre o fenômeno e o contexto não são claramente definidas e na situação em que múltiplas fontes de evidência são utilizadas.

O SL demonstra características que o diferem dos outros jogos de MMORPG e o torna um atrativo a pesquisas nesta área, pois garante a propriedade das criações aos residentes, e a possibilidade de fazer o que quiserem, o que serve também como motivação para o usuário. Esta é a saída encontrada pelos seus criadores para garantir uma economia crescente e saudável, em que os jogadores possuem os mesmos direitos de propriedade semelhante aos da vida real (TERDIMAN, 2008, p. 7).

Outra característica própria do jogo é que aos residentes é também permitida a compra de itens, criando assim uma experiência de consumo para os usuários que optarem não por fazer, mas por gastar dinheiro adquirindo artefatos que outros avatares fizeram e puseram a venda, mostrando aquilo que os consumidores estão necessitando e por vezes não encontram no mundo real.

A seleção de respondentes ocorreu de forma aleatória e simples. Todavia, essa seleção foi cuidadosa, no sentido de priorizar a qualidade das informações. Quanto aos respondentes, nesta pesquisa, foi composto por residentes do Second Life que tinham de alguma forma despendido dinheiro com o jogo, como também, pelos que participavam do jogo sem efetuar compra. No total foram dois grupos de sujeitos que trouxeram informações relevantes ao estudo: os avatares que não consomem e aqueles que consomem.

Como método de coleta de dados, utilizou-se o método de observação participante para tentar compreender os fenômenos que estão sendo estudados a partir da perspectiva dos participantes como sugere Godoy (1995). Esse tipo de observação requer a participação real do pesquisador na vida da comunidade estudada, podendo o observador assumir o papel de membro do grupo e chegar ao conhecimento do mesmo a partir do seu interior. Além da observação participante, diálogos e entrevistas semiestruturadas foram realizadas. Com base nos preceitos do diálogo etnográfico, houve interação com os consumidores de produtos vendidos nesse ambiente e com os não-compradores. Esta etapa da pesquisa foi realizada durante nove meses (fase exploratória). Enquanto que a entrevista 
semiestruturada foi aplicada logo em seguida durante o mês subsequente, com o intuito de consolidar o alcance dos objetivos propostos no estudo com apenas consumidores.

O primeiro contato com um residente se deu no início da experiência no jogo, que ocorreu na fase exploratória, conhecendo os diferentes ambientes foi possível se relacionar com avatares hospitaleiros dispostos a ajudar e tirar dúvidas. Passado um mês de conversas esporádicas, surgiu um avatar que viria a ser o que com mais frequência ofereceu ajuda. Por meio dele tomou-se conhecimento de várias funcionalidades e peculiaridades do SL, além do fato de conhecer vários jogadores que compunham o seu círculo de amizade.

A análise dos dados foi realizada levando-se em consideração todas as informações colhidas com o apoio do embasamento teórico. A análise de conteúdo foi o modo com que os dados foram analisados com o propósito de alcançar o objetivo da pesquisa.

\section{DISCUSSÃO DOS RESULTADOS}

A presente pesquisa tem como objetivo geral descrever os fatores que mais levam os usuários a empregarem recursos financeiros neste tipo de ambiente virtual. Para tanto, inicialmente, são apresentadas algumas informações da dinâmica do Second Life. Como característica marcante, o presente trabalho possui um único objeto de estudo que é o jogo Second Life. Para ter acesso ao SL basta que se crie gratuitamente uma conta no seu site oficial e se faça o download de qualquer programa que possa conectá-lo a este "mundo". O viewer é encontrado em qualquer site de busca, além do viewer oficial disponibilizado pela Linden Lab existem vários outros que possuem diferentes funcionalidades.

Quando o login é feito, o contato inicial com outros usuários é simples, como frisam Hinsch e Bloch (2009, p. 49) "[...] não existe necessidade de viagens ou de marcar encontros. [...] Um residente pode simplesmente mover-se em direção a outro jogador e dizer ou escrever 'Oi'”".

O SL é um lugar onde existem possibilidades ilimitadas e inúmeras opções do que fazer, um lugar onde praticamente tudo é admissível. Apesar da possibilidade de realização de qualquer fantasia e da tolerância dos residentes para com o jeito de ser dos outros usuários do jogo, em alguns locais é proibido voar, deixar cair objetos no chão, entre outras proibições que ficam a critério de quem é dono do lugar.

Além disso, a própria Linden Lab conta com seis grandes regras do jogo que se desobedecidas podem gerar a expulsão do avatar deste ambiente virtual, são elas: (i) intolerância, que são quaisquer

Revista de Administração e Inovação, São Paulo, v.12, n.1, p.98-120, jan./mar. 2015. 
tipos de ações que marginalizem, menosprezem ou difamem indivíduos ou grupos, o que acaba minando a troca de ideias e diminuindo a comunidade; (ii) assédio, que é caracterizado pela conduta ou comunicação de forma grosseira, intimidante ou ameaçadora, que constitua um avanço sexual ou a solicitação de favores sexuais ou comportamentos que de outra forma causem mal-estar ou tensão; (iii) agressões, que no jogo são atirar, empurrar ou atropelar outro residente em uma área segura, criar ou usar objetos que única ou persistentemente sejam dirigidos a outro residente e o impedem de se divertir no Second Life; (iv) privacidade, que garante aos residentes o direito a um certo nível de privacidade em relação ao usufruto do SL; (v) regiões, grupos e listas de conteúdo adulto, que são restritas apenas a áreas destinadas a este tipo de informação; e (vi) perturbação da paz, como a intromissão de eventos agendados, a transmissão insistente de publicidade indesejada, o uso de sons repetitivos, seguir ou armazenar itens ou outros objetos que intencionalmente diminuam o desempenho do servidor ou restrinjam a capacidade de outro residente de aproveitar o ambiente do jogo.

O SL possui um relógio próprio ajustado ao Greenwich Mean Time (GMT) -7:00, este é o mesmo fuso horário do estado da Califórnia nos Estados Unidos, onde está localizada a sede da Linden Lab e os residentes em sua maioria marcam os compromissos do jogo de acordo com esse relógio, não de acordo com o seu próprio fuso.

No Second Life é possível se fazer compras de terras e em alguns destes ambientes do jogo pode-se perceber a existência de uma hierarquia presente entre os participantes de determinados grupos, o que os tornam responsáveis pelos espaços pertencentes ao grupo. Alguns avatares chegam a receber denominações como 'Rainha' e 'Rei', para designar sua importância para os demais e muitos destes grupos possuem conselhos formados por alguns participantes escolhidos pelos monarcas donos das terras. Essa escolha deve-se em sua maioria a ajuda fornecida pelos outros avatares às necessidades do grupo, bem como a frequência com que estão presentes no jogo. Existem três grandes tipos de avatares, são eles: (i) humanos, que são avatares com características de seres humanos; (ii) ferais, aqueles que são bichos; e (iii) furries, avatares que são a mistura entre os ferais e os humanos.

Após a explanação sobre o jogo, são apresentados os resultados da pesquisa.

\subsection{Motivos de compra}

A Figura 1 revela os fatores que mais levam os usuários a empregarem recursos financeiros neste tipo de ambiente virtual. Verificou-se que a disponibilidade de recursos financeiros, a busca pela 
melhoraria da aparência dos seus avatares, o preço e a expressão da individualidade são principais motivos de compra dos residentes entrevistados.

\begin{tabular}{|c|c|c|c|}
\hline \multicolumn{4}{|c|}{ MOTIVOS DE COMPRA } \\
\hline $\begin{array}{l}\text { Disponibilidade de } \\
\text { recursos financeiros }\end{array}$ & $\begin{array}{c}\text { Melhoria da } \\
\text { aparência do avatar }\end{array}$ & Preço & $\begin{array}{c}\text { Expressão da } \\
\text { individualidade }\end{array}$ \\
\hline $\begin{array}{l}\text { Respondente H: i } \\
\text { honestly cant } \\
\text { remember the first } \\
\text { thing i bought. lol but } \mathrm{i} \\
\text { probably bought it } \\
\text { because i figured the } \\
\text { money isnt going } \\
\text { anywhere, i might as } \\
\text { well use it. }\end{array}$ & $\begin{array}{l}\text { Respondente F: I buy } \\
\text { fancy dresses and } \\
\text { such; } \\
\text { Respondente J: to } \\
\text { make my av look } \\
\text { better; Respondente E: } \\
\text { i wanted to look good } \\
\text { on here; } \\
\text { Respondente B: my } \\
\text { look. }\end{array}$ & $\begin{array}{l}\text { Respondente I: ... it's } \\
\text { cheaper in here to own } \\
\text { a horse then it is in } \\
\text { real life; } \\
\text { Respondente G: One } \\
\text { of my friends says that } \\
\text { they see buying things } \\
\text { for avatars as 'cheap } \\
\text { entertainment' an I } \\
\text { agree... }\end{array}$ & $\begin{array}{c}\text { Respondente C: i just } \\
\text { love shopping hun and } \\
\text { i want to dress } \\
\text { different from the rest; } \\
\text { Respondente G: ... } \\
\text { We buy these items to } \\
\text { express ourselves, and } \\
\text { be individual. }\end{array}$ \\
\hline
\end{tabular}

Figura 1. Principais motivos de compra apresentados

Fonte: Elaboração das autoras.

Verificou-se que o motivo de compra mais citado pelos residentes entrevistados foi o de melhorar a aparência dos seus avatares. Foi constatado também que alguns avatares desejam expressar sua individualidade por meio da compra de produtos no SL, como afirmou a Respondente G dizendo que faz esse tipo de compra para expressar a si própria e ser individual. Os Respondentes A e H indicam a disponibilidade de dinheiro nas contas do jogo como um dos motivos de compra quando afirmaram que se não gastassem o dinheiro, ele sozinho não vai a lugar nenhum.

Outro fator que leva os residentes a empregarem dinheiro no jogo é o preço dos produtos no SL, que é bem menor do que o preço dos seus equivalentes na vida real. Tal argumento foi defendido por Hinsch e Bloch (2009, p. 56) justificando este fator ao dizer que isso se dá pela taxa de câmbio dos Lindens Dólares. Trata-se da moeda do jogo. A aquisição mínima de Lindens permitida pelo jogo é de L\$ 550 por compra, o que equivale a aproximadamente US\$ 2,50 que “permite pessoas que não são ricas comprar itens para os seus avatares com os quais eles não podem nem sonhar na vida real”. A compra de um vestido de noiva na vida real que varia, em média, entre $\mathrm{R} \$ 1.000$ e $\mathrm{R} \$ 2.000$, pode ser feita no jogo por L \$400, ou seja, menos de $\mathrm{R} \$ 3,20$.

Em consonância com o que afirmam Hirschman e Holbrook (1982) sobre a compra hedônica de itens fantasiosos para suprirem necessidades daquilo que desejam que seja real, oito dos entrevistados afirmaram adotar esta prática no jogo. Animais de estimação, principalmente cavalos, são frequentemente comprados, tendo sido citados pelo Respondente I: “horses lmao!”, este fato está ligado, além do hedonismo, com o motivo de que comprar cavalos no Second Life é mais barato que na 
vida real. Outra entrevistada que afirmou fazer esse tipo de compra foi a Respondente C quando disse: "yes [...] $i$ dont have horses", neste momento da conversa ela havia sido perguntada sobre a compra de itens que não possuía na vida real, mas sim no SL. No SL o mercado de cavalos é bastante amplo, havendo criadores, leilões e raças tal qual na vida real.

Ainda se tratando de compras hedônicas, podem ser mencionados outros relatos em relação à demonstração de sua vontade para efetivar a primeira compra no jogo. Avatares fantasiosos como vampiros (avatares que podem morder outros residentes conseguindo assim um pedaço das suas “almas", para torná-los filhos e filhas) e dragões são comprados para substituir a personalidade que os residentes desejam, mas sabem ser inexistente na vida real. As informações da Respondente C: "Vampire Hud [...] it is just a fantasy of mine since $i$ was a kid", e da Respondente I: "my vampire hud [...] because the reason i came to sl was to be a vampire" reforçam que a ideia de poder se transformar em certos tipos de criaturas é um atrativo a mais para a realização de compras no jogo. É interessante explicar o significado de HUD (Heads'up Display) que é um mostrador que monitora as ações de certas características dos avatares. O relato da Respondente G: "First thing I ever bought from here was a $1 L \$$ dragon avatar. I really like dragons as well, and I was so excited when a dragon avatar came up in my search" indica que a possibilidade de transformar-se em diferentes animais também inspira os jogadores a continuar comprando.

Parmentier e Rolland (2009) apresentaram em seu trabalho que as empresas de grande porte do mundo real levaram suas lojas ao mundo virtual, porém, do grupo de residentes entrevistados apenas o Respondente A afirmou conhecer a existência delas quando disse: “eles tem suas lojas aqui também [...] há um mercado aqui [...] grande [...] marcas só de SL e marcas de RL também [...] eu tenho uma coleção de calçados adidas [...] toyota tem modelos de autos para SL também”.

Portanto, o estudo contribui para o preenchimento de espaço na lacuna de informações existentes sobre este tipo de variável, acrescentando informações aos estudos de Parmentier e Rolland (2009) por confirmar sua teoria de melhoramento e metamorfose como perspectivas sobre as identidades dos avatares, e à pesquisa de Shelton (2010) quando demonstra que fantasia e metamorfose também são motivos de compra.

\subsection{Elementos mais valorizados}

Analisando-se as respostas obtidas por meio das entrevistas, quatro são os elementos mais valorizados pelos jogadores. O mais citado nas entrevistas é a tolerância existente no jogo. Com isso,

Revista de Administração e Inovação, São Paulo, v.12, n.1, p.98-120, jan./mar. 2015. 
os avatares podem sentir-se à vontade para fazerem e usarem o que quiserem sem se preocupar, pois suas ações não afetam a relação com outros avatares.

Os relatos, que podem ser encontrados na Figura 2, confirmam o que foi explicado por Hinsch e Bloch (2009, p. 46) quando afirmam que "os usuários do Second Life têm uma considerável liberdade de fazer o design e criar o seu próprio avatar". O que se aproxima do que é defendido por Kamel (2009, p. 30), para o autor "o pensamento de consumo pós-moderno considera que a experiência de consumo não está destinada a reconciliar diferenças e paradoxos, mas permitir que eles existam livremente". Tal entendimento também é compartilhado por Hinsch e Bloch (2009, p. 46), eles explicam que "enquanto a maioria das leis físicas existe no mundo virtual, o Second Life toma algumas liberdades, os residentes são capazes de voar e ainda de teletransportarem-se de um lugar a outro".

As relações afetivas de amizade que são criadas dentro do jogo são em alguns casos fortes, fazendo com que alguns residentes considerem outros membros de sua família no jogo. Para alguns usuários, este tipo de relação é a característica do SL que tem mais valor. Esta evidência pode ser encontrada nas explicações dos Respondentes A, B e $\mathrm{H}$ evidenciando o que foi apresentado por Castronova (2001) que afirma que depois do fechamento de um mundo virtual, os usuários sentem a perda tanto do mundo quando das relações que foram uma parte significante das suas vidas.

Em acréscimo, ressalta-se para os investidores que pretendem entrar no ramo de lojas em ambientes virtuais, tais como o SL, a preferência dos usuários do jogo por determinadas lojas se dá principalmente pela identificação com o estilo de produtos oferecidos. Pode-se perceber, portanto, que os usuários do Second Life valorizam, principalmente, as relações de amizade e a família construída no jogo, as possibilidades ilimitadas oferecidas pelo ambiente do SL, a tolerância dos outros usuários para com os seus estilos e/ou atitudes, e ainda os cenários do jogo.

\begin{tabular}{|c|c|c|c|}
\hline \multicolumn{5}{|c|}{ ELEMENTOS MAIS VALORIZADOS } \\
\hline Amigos e/ou família & Cenários & $\begin{array}{c}\text { Possibilidades } \\
\text { ilimitadas }\end{array}$ & Tolerância \\
\hline $\begin{array}{c}\text { Respondente A: eu } \\
\text { gosto das amizades, e } \\
\text { claro, de minha familia } \\
\text { virtual [...] minha } \\
\text { esposa, e filhos e seus } \\
\text { filhos; }\end{array}$ & $\begin{array}{c}\text { Respondente E: some } \\
\text { places, the scenery } \\
\text { looks good; } \\
\text { Respondente H: well } \\
\text { some of the scenic } \\
\text { Respondente B: the } \\
\text { places [...] its like art. }\end{array}$ & $\begin{array}{c}\text { Respondente I: [...] i } \\
\text { can create my own } \\
\text { antasy world in here } \\
\text { life sometimes; } \\
\text { Respondente D: the } \\
\text { boundless options. }\end{array}$ & $\begin{array}{c}\text { Respondente F: How } \\
\text { most people are rather } \\
\text { accepting; } \\
\text { Respondente J: the } \\
\text { possibility of doin } \\
\text { anythng i want without } \\
\text { being judged; }\end{array}$ \\
\hline
\end{tabular}

Figura 2. Elementos do ambiente virtual mais valorizados pelos usuários

Fonte: Elaboração das autoras 
Após a discussão dos resultados relacionados aos elementos mais valorizados, apresentam-se as respostas internas dos jogadores entrevistados.

\subsection{Respostas internas}

Salienta-se que o esqueleto do marketing experiencial é constituído por duas características: os modelos experienciais estratégicos (MEEs), que são o sentido, o sentimento, pensamento, ação e identificação, e os provedores de experiências, os ProExs, que são o espaço ambiental, as pessoas, a presença do produto, as co-marcas, as comunicações, a mídia eletrônica e a identidade visual e verbal (SCHMITT, 2002). Esta seção tem como escopo os MEEs que constituem as respostas internas dos indivíduos. Especificamente, as respostas internas investigadas são relativas à compra realizada no ambiente do jogo, a maioria das respostas obtida foi positiva com a informação dos residentes de que a compra os deixavam felizes, animados e algumas vezes deslumbrados, porém alguns residentes apresentaram o arrependimento como uma resposta negativa do ato da compra. Além disso, alguns residentes informaram que a sensação de compra no Second Life era em alguns aspectos parecida com as sensações sentidas na vida real. Portanto, são expostos relatos dos residentes para que seja possível discuti-los com o apoio do referencial teórico.

Tais respostas estão inseridas no segundo módulo experiencial estratégico (MEE) proposto por Schmitt (1999) que está relacionado ao sentimento dos clientes estimulado pelo marketing experiencial, dados os vários aspectos que podem ser observados nas respostas apresentadas na Figura 3 como, a felicidade presente nas respostas dos Respondentes F, H e outros, a animação citada pelos Respondentes C, G e I, bem como o deslumbramento do Respondente B. Além do arrependimento em algumas compras descrito pelos Respondentes C, F e I.

\begin{tabular}{|c|c|c|c|c|}
\hline \multicolumn{5}{|c|}{ RESPOSTAS INTERNAS } \\
\hline \multirow[b]{2}{*}{$\begin{array}{l}\text { Respostas } \\
\text { internas } \\
\text { relativas às } \\
\text { compras } \\
\text { feitas no } \\
\text { jogo }\end{array}$} & Animacão & Arrependimento & Felicidade & Deslumbramento \\
\hline & $\begin{array}{l}\text { Respondente C: } \\
\text { i feel excited; } \\
\text { Respondente I: } \\
\text { excited! lol!; }\end{array}$ & $\begin{array}{l}\text { Respondente F: } \\
\text { Like I really } \\
\text { shouldn't, but I } \\
\text { know that it's the } \\
\text { only way I'll get } \\
\text { things that I like; } \\
\text { Respondente C: }\end{array}$ & $\begin{array}{l}\text { Respondente F: I } \\
\text { figure out what I } \\
\text { want, and I guess I'm } \\
\text { happy when I buy it; } \\
\text { Respondente E: i } \\
\text { bought my body } \\
\text { parts, that made me }\end{array}$ & $\begin{array}{c}\text { Respondente H: i } \\
\text { was usually amazed } \\
\text { by it. like i had never } \\
\text { seen it before. it was } \\
\text { so different; } \\
\text { Respondente B: i fell } \\
\text { shocked or amazed. }\end{array}$ \\
\hline
\end{tabular}

Revista de Administração e Inovação, São Paulo, v.12, n.1, p.98-120, jan./mar. 2015. 


\begin{tabular}{|c|c|c|c|c|}
\hline & & regrets sometimes; & $\begin{array}{l}\text { happy; } \\
\text { Respondente B: i feel } \\
\text { wonderful. }\end{array}$ & \\
\hline & Aceitação & Felicidade & Relaxamento & Tédio \\
\hline $\begin{array}{l}\text { Respostas } \\
\text { internas } \\
\text { relativas à } \\
\text { presença no } \\
\text { ambiente } \\
\text { do jogo }\end{array}$ & $\begin{array}{l}\text { Respondente F: } \\
\text { Accepted [...]. } \\
\text { Respondente G: } \\
\text { "I feel very } \\
\text { accepted here, } \\
\text { like I can dress } \\
\text { how I want, and } \\
\text { do things } \\
\text { without being } \\
\text { judged. [...]. }\end{array}$ & $\begin{array}{l}\text { Respondente H: } \\
\text { "iv gone through } \\
\text { so many emotions } \\
\text { on here just like in } \\
\text { rl. but my most } \\
\text { dominant feeling } \\
\text { would be the } \\
\text { happiness to be } \\
\text { reconnected with } \\
\text { the ones i love; }\end{array}$ & $\begin{array}{l}\text { Respondente } \mathrm{J} \text { : i feel } \\
\text { at ease.i get all my } \\
\text { stress out here.i jst } \\
\text { feel relaxed. }\end{array}$ & $\begin{array}{l}\text { Respondente } \mathrm{F}:[\ldots] \\
\text { if a bit bored at } \\
\text { times; } \\
\text { Respondente } \mathrm{I} \text { : i feel } \\
\text { most times boredom. }\end{array}$ \\
\hline
\end{tabular}

\section{Figura 3. Respostas internas dos residentes}

Fonte: Elaboração das autoras

Fazer compras no jogo é similar a sensação da vida real. Sobre esse assunto, o Respondente A explica que: "sempre é quase como comprar na RL”. Quando a Respondente H afirma que: "well $i$ still make sure that what $i$ buy its what i really want. like in $r l$ how you look around until you can find the best. well $i$ do that here too. $i$ hate wasting money [...]" é apresentada uma semelhança com o ato da pesquisa de compra, onde o consumidor visita várias lojas para identificar aquela que oferece os melhores produtos e/ou melhores condições. A Respondente I informa que: "i shop when i'm bored on here and $i$ shop when i feel like crap in real life. so it's the same”, simbolizando o consumo como forma de relaxamento.

Ainda com relação às respostas internas, mas, dessa vez, voltadas à presença no ambiente do jogo, pode-se perceber através das respostas que assim como na compra existem três sentimentos positivos e apenas um negativo. As afirmações positivas dizem respeito à felicidade, o sentimento de aceitação por parte dos outros residentes e ainda o relaxamento proporcionado pelo jogo. O único aspecto negativo foi apresentado pelas Respondentes F e I, e diz respeito ao tédio que alguns residentes afirmam sentir em certos momentos.

Com relação a confundir emoções do SL com emoções da vida real, seis dos respondentes afirmaram já ter feito algum tipo de confusão pelo menos uma vez, sendo que para os Respondentes E, F e I este foi um tipo de experiência experimentada apenas uma vez, com a qual aprenderam a não fazer mais esse tipo de confusão. Já para as Respondentes B, D e H, não têm como fazer esta distinção, posto que apesar de serem dois mundos o avatar e quem está por trás dele no fim são a mesma pessoa. Emoções também estão ligadas à criação, no Second Life, daquilo que os usuários sentem falta na vida real, já que das respostas obtidas duas estão ligadas à criação de laços fortes com outros residentes. 
Eroglu, Machleit e Davis (2001) explicam que as lojas virtuais não exploram em sua totalidade os sentidos que são captados pelos ambientes de loja reais, fato evidenciado neste estudo. Apenas três sentidos foram citados pelos respondentes quando perguntados sobre quais deles eram estimulados pelo ambiente de imersão do SL. Dos três a visão foi citada com mais frequência, seguida da audição e do tato.

Portanto, constata-se que as respostas internas dos residentes são deslumbramento e arrependimento correspondendo às respostas cognitivas, animação e felicidade como respostas afetivas. Tais reações corroboram o pensamento de Peter e Olson (2009) quando afirmam que o sistema cognitivo e o sistema afetivo podem trabalhar em conjunto para a tomada de decisões, e neste caso para a experiência de consumo no SL.

\subsection{Permanência no jogo}

Quanto aos motivos que fazem com que os usuários permaneçam no jogo, obteve-se o seguinte resultado: a influência dos relacionamentos de amizade e a interação com a família do SL na permanência dos usuários no jogo, o escapismo, com relação à vida real, e o sentimento de responsabilidade de alguns usuários para com alguns aspectos do jogo são os principais influenciadores. Também foram identificados: o motivo que fez os residentes conectarem-se ao jogo pela primeira vez, as suas primeiras impressões, a experiência mais especial que vivenciaram no jogo e os motivos que os fazem sair do ambiente de jogo e voltarem à vida real.

A afirmativa de Hinsch e Bloch (2009, p. 49) que "a experiência no Second Life é tão diferente dos jogos tradicionais que rapidamente se torna claro que a interação social é o que motiva as pessoas a habitar este mundo" é confirmada pelas respostas apresentadas pelos Respondentes D, E, F, G e J, que afirmam ser principalmente para saber notícias das amizades e da família que criaram no jogo que continuam se logando, pois assim podem passar um tempo com eles.

"Os jogadores escapam da realidade e dos seus problemas através da imersão no mundo virtual e pesquisadores estão divididos quanto a essas implicações" (KAMEL, 2009. p. 28). A afirmação desta autora é confirmada nos achados desta pesquisa ao identificar que alguns usuários têm suas contas no Second Life como uma forma de escapar dos problemas e não pensar nos estresses causados pela realidade. Esses resultados também estão de acordo com que é postulado por Hinsch e Bloch $(2009$, p. 50) quando dizem que "espera-se que os usuários do Second Life estejam mascarados como algo frequentemente diferente da sua pessoa no mundo real. Deste modo, o potencial de fuga é bem maior no Second Life que em outros sites de relacionamentos". 
As respostas dadas pelos Respondentes A e $\mathrm{H}$ demonstram a responsabilidade para com alguns aspectos do jogo como motivadora da permanência dos usuários, o que vem a legitimar a afirmação de que "[...] alguns jogadores consideram ter um papel de responsabilidade no jogo que os ajudam a serem mais auto-confiantes na vida real" (KAMEL, 2009. p. 28).

Os motivos que levaram os jogadores a experimentarem pela primeira vez foram a curiosidade de saber como era o ambiente do jogo após terem recebido informações sobre ele em diversos locais. Neste primeiro contato com a vida no jogo, a maioria dos respondentes não teve uma boa primeira impressão, alegando que acharam o jogo confuso, complexo irritante e chato. O Respondente A explica que: "como algo muito complexo [...] grande [...] difícil [...] e como se ve fora chegada ao outro mundo [...] tudo diferente [...] coisas q vc não entende", quando se entra pela primeira vez no jogo você é levado a ilha de orientação pública, onde existem inúmeros avatares e você pode perceber a dimensão do jogo pois a ilha possui vários ambientes a serem explorados. Respondente C: "it was boring”, neste caso pela falta de metas apresentadas pelo jogo. Respondente D: “it confused me”, pois o avatar entrou em um ambiente com chat por voz e não conseguia entender o que estavam falando ou o que ela foi fazer ali.

Por outro lado, alguns residentes tiveram respostas positivas no primeiro contato com o jogo, acreditando que seria um ótimo lugar para conhecer novas pessoas e fazer amigos, como acreditam a Respondente J: "the first impression $i$ had about sl for me was that it would be a site for me to make friends and play it how $i$ would hav liked my life to be like" e o Respondente E: "yes,i thought it was great.good to meet people”. Não houve nenhuma resposta que pudesse corroborar o exposto por Hinsch e Bloch (2009, p. 49) de que "um novo jogador exposto ao Second Life pela primeira vez pode achar que o mais interessante de toda a experiência é que não se precisa fazer nada”. Por isso, esta pesquisa aponta um resultado diferente daquilo que foi exposto em pesquisa anterior.

Procurou-se saber ainda qual teria sido a experiência mais marcante de toda a vida do usuário no SL. A maioria dessas experiências envolvia outro avatar como as vividas pelos Respondentes A, E e J, que tiveram relações sérias com outros residentes, a Respondente $\mathrm{H}$ que teve a oportunidade de ter filhos no jogo, e as Respondentes B e F que alegaram ter feito sexo. Apenas três das respostas estavam ligadas a outros tipos de experiência. Que tem a transformação em vampiro como principal experiência segundo a Respondente I: "my most outstanding experience was becoming a vampire [...]", a exploração de diversos lugares como exposto por Respondente D: “i love sims with exploring stuff”, e a experiência de ter visitado as estrelas como afirma Respondente G: "Ahh The best experience I had about SL was with a friend of mine, she and her partner own a Science organisation. And she took me into space, on a rocket, it was fantastic. I enjoyed it very much :)”. 
Quanto ao que faz com que os usuários saiam deste mundo de imersão que é o Second Life, algumas das motivações apontam para o próprio jogo, como quando fica chato ou não existe nenhum amigo online. $\quad$ Portanto, na Figura 4 observam-se os motivos que fazem com que os usuários permaneçam no jogo. Em primeiro lugar são os amigos e a família que os residentes criaram dentro do ambiente do SL, depois, o sentimento de responsabilidade que eles nutrem para com alguns aspectos do jogo, além do escapismo dos problemas que os sujeitos possuem na vida real.

\begin{tabular}{|c|c|c|}
\hline \multicolumn{3}{|c|}{ PERMANÊNCIA NO JOGO } \\
\hline Amigos/Família & $\begin{array}{l}\text { Escapismo } \\
\end{array}$ & Responsabilidades no jogo \\
\hline $\begin{array}{l}\text { Respondente F: I have friends } \\
\text { here. Friends that i'd have never } \\
\text { met if I hadn't joined; } \\
\text { Respondente J: see how my sl } \\
\text { friends are doin; } \\
\text { Respondente E: i have some } \\
\text { good friends on here i like to } \\
\text { see; }\end{array}$ & $\begin{array}{l}\text { Respondente C: to escape from } \\
\text { reality and not think about } \\
\text { stress in RL; } \\
\text { Respondente J: to get outa } \\
\text { stress [...]; } \\
\text { Respondente I: cause i'm bored } \\
\text { most days lol!. }\end{array}$ & $\begin{array}{l}\text { Respondente A: eu tenho uma } \\
\text { vida aki; } \\
\text { Respondente H: well being } \\
\text { second to the queen of the clan, } \\
\text { i have tons of responsibilities } \\
\text { that cant be put aside. i also } \\
\text { have my horses to tend to. they } \\
\text { keep me going when and if } \\
\text { nothing else does. }\end{array}$ \\
\hline
\end{tabular}

\section{Figura 4. Motivos de permanência no jogo}

Fonte: Elaboração das autoras

Apresentados os resultados obtidos, passa-se, então, a apresentar as considerações finais.

\section{CONSIDERAÇÕES FINAIS}

O presente estudo foi motivado pela expectativa de que se no ambiente do Second Life existe a possibilidade de fazer compras de diversos itens, então, havia experiência de consumo que deveria ser investigada. O jogo possui características peculiares de jogabilidade permitidas pelas ilimitadas possibilidades oferecidas e pelo fato de que nenhum avatar é controlado por computador, eles são de fato pessoas de diversos locais do mundo. Os resultados obtidos demonstraram que o ambiente do jogo proporciona aos seus residentes experiências significativas, não só experiências relacionadas ao consumo de produtos dentro do jogo, mas também, identificou-se a influência das relações afetivas criadas e mantidas no ambiente. 
Em se tratando de lojas ambientadas no Second Life, a preferência dos sujeitos por algumas específicas se dá por três características principais: a primeira e mais recorrente é se o tipo de produto oferecido está relacionado ao estilo que os jogadores desejam transparecer com seus avatares. Outra característica interessante é o preço menor de produtos oferecidos por algumas lojas. Por fim, o market place que é uma espécie de "mercado livre" criado pelo próprio Liden Lab onde os usuários podem vender suas posses, que segundo dois respondentes fazem com que a pesquisa de produtos se torne mais fácil.

Por meio da interpretação dos dados coletados, pôde-se identificar que os sentimentos relacionados ao processo de compra dentro do ambiente analisado são em algum nível parecido com o que é sentido pelos respondentes ao realizarem compras na vida real e em algumas situações até mais prazerosos. As respostas foram divididas quando o assunto tratado foi a proximidade entre as emoções vividas no jogo e na vida real. Parte dos entrevistados faz confusão entre o ambiente real e o virtual. Para eles há uma mistura de emoções e o que sentiam pelos amigos e/ou família do jogo permaneciam lá quando não estavam logados no jogo. Ainda a respeito dessas emoções quando perguntados se já haviam criado algo no jogo que lhes faziam falta na vida real duas das respostas obtidas eram relacionadas a laços fortes com outros avatares e a infância perfeita na concepção de um respondente.

Demonstrando um forte estímulo aos sentimentos dos jogadores, os entrevistados elencaram como emoções mais frequentes despertadas pela presença no ambiente do jogo a felicidade, a aceitação e o relaxamento, mas, existiram entrevistados que sentiram tédio enquanto estavam jogando.

Embora o Second Life seja um ambiente de imersão, o computador se torna um fator limitante do estímulo dos sentidos no jogo uma vez que os jogadores não têm a possibilidade de sentir o aroma do ambiente em que estão localizados, nem o sabor dos alimentos que os seus avatares ingerem. De acordo com a pesquisa, o sentido mais utilizado é a visão, citada como principal fonte de interação entre a pessoa por trás do avatar e o jogo. Em segundo lugar, aparece a audição por ser estimulada pelo som do ambiente, por sons emitidos pelo avatar e ainda pela possibilidade de conversação através da fala oferecida pelo jogo. Por último, o tato foi lembrado por alguns sujeitos como sendo um sentido que era estimulado pelas experiências de jogabilidade.

Os motivos que levaram os sujeitos a experimentarem o jogo foram principalmente a curiosidade, por terem ouvido falar sobre este ambiente em algum lugar e sentirem vontade de conhecer o que o Second Life oferecia, além de algumas indicações de amigos que já faziam parte do jogo. As primeiras impressões que os sujeitos tiveram, entretanto, foram em sua maioria negativas como: jogo confuso, complexo, irritante e chato. Apenas foram identificadas duas respostas positivas 
de residentes que acharam que o jogo seria um ótimo lugar para se fazer novos amigos e ainda possuir a vida que se desejavam.

Com relação à hora em que vão deixar o jogo e voltarem para as suas vidas reais, alguns dos respondentes identificaram que em dado momento o jogo fica chato, quer seja pela falta de amigos online, quer seja pela falta do que fazer, sendo esta a hora de sair do jogo. Ademais foram citados como motivos de saída do jogo suprir necessidades físicas e ou fisiológicas e resolver problemas na vida real. Por fim, indica-se a realização de estudos em ambientes de jogos virtuais que considerem o interacionismo simbólico. Além disso, sugere-se investigar a visão e o papel dos empreendedores que disponibilizam produtos no SL.

\section{REFERÊNCIAS}

BONSU, Samuel K.; DARMONDY, Aron. Co-creating Second Life: market-consumer cooperation in contemporary economy. Journal of macromarketing, v. 28, n. 4. Toronto: Sage Publications, 2008. p. 355-368.

CASTRONOVA, Edward. Virtual Worlds: a first-hand account of market and society on the cyberian frontier. CESifo Working Paper Series. n. 618. 2001. 41p.

EROGLU, Sevgin A. MACHLEIT, Karen A. DAVIS, Lenita M. Atmosferic qualities of online retailing: a conceptual model and implications. Journal of Business Research, n. 54. New York: Elsevier, 2001. p. 177-184.

FLÔR, Priscilla P.; UMEDA, Guilherme M. Branding sensorial: a integração do marketing de experiências às estratégias de comunicação. In: Congresso Brasileiro de Ciências da Comunicação, 32, 2009, Curitiba. Anais... Curitiba: Sociedade Brasileira de Estudos Interdisciplinares da Comunicação, 2009. p. 1-14.

FONSECA, Marcelo Jacques et al. Tendências sobre as comunidades virtuais da perspectiva dos prosumers. RAE eletrônica. São Paulo, v. 7, n. 2, art. 24, jul/dez. 2008.

GODOY, Arilda Shmidt. Introdução a pesquisa qualitativa e suas possibilidades. Revista Administração de Empresas. São Paulo, v. 35, n. 2. mar/abr. 1995, p. 57-63.

HAENLEIN, Michael; KAPLAN, Andreas M. Flagship brand stores within virtual worlds: the impact of virtual store exposure on real-life attitude toward the brand and purchase intent. Recherche et applications en marketing. v. 24, n. 3. [S.1.], 2009. p. 58-79. 
HINSCH, Christian; BLOCH, Peter H. Interaction Seeking in Second Life and Implications for Consumer Behavior. In: Virtual Social Identity and Consumer Behavior. Armonk: M. E. Sharpe, 2009. $230 \mathrm{p}$.

HIRSCHMAN, Elizabeth C.; HOLBROOK, Morris. Hedonic Consumption: Emerging Concepts, Methods and Propositions. In: Journal of Marketing. Chicago, v. 46, n. 3, p. 92-101, 1982.

HOLBROOK, Morris; HIRSCHMAN, Elizabeth C. The Experiential Aspects os Consumption: Consumer Fantasies, Feelings, and Fun. In: Journal of Consumer Research. v. 9, p. 132-140, 1982.

KAMEL, Leila El. For a better exploration of metaverses as consumer experiences. In: Virtual Social Identity and Consumer Behavior. Armonk: M. E. Sharpe, 2009. 230 p.

LARENTIS, Fabiano. Premissas e perspectivas a respeito do consumidor. In: Comportamento do Consumidor e Marketing de Relacionamento. 1.ed. Porto Alegre: IESDE, 2008. p. 9-20.

LEIGH, James H.; GABEL, Terrance G.Symbolic Interactionism: Its Effects on Consumer Behavior and Implications for Marketing Strategy. The journal of Services Marketing, v. 6, n. 3, p. 5-9, 1992.

LINDEN LAB, 2010. Disponível em <http://lindenlab.com/pressroom/releases/pt_22_09_09> Acesso em $24 / 10 / 2010$.

NEVES, José Luis. Pesquisa Qualitativa - características, usos e possibilidades. Caderno de Pesquisas em Administração. v. 1, n. 3, $2^{\circ}$ semestre. São Paulo: USP, 1996. p. 1-5.

OKADA, Erica M. Justification Effects on Consumer Choice of Hedonic and Utilitarian Goods. In: Journal of Marketing Research. v. 42, 2005. p. 43-53.

PARMENTIER, Guy; ROLLAND, Sylvie. Consumers in virtual worlds: identity building and consuming experience in Second Life. In: Recherche et Applications en Marketing. v. 24 n. 3/2009. p. 43-55.

PETER, J. Paul; OLSON, Jerry C. Comportamento do consumidor e estratégia de marketing. 8. ed. São Paulo: McGraw-Hill, 2009. 555 p.

SCHMITT, Bernd H. Experiential Marketing. In: Journal of Marketing Management. n. 15. [S.1]: Westburn Publishers Ltd, 1999. p. 53-67.

SCHMITT, Bernd H. Marketing experimental. Tradução Sara Gedanke. São Paulo: Nobel, 2000. p. $11 ; 41 ; 76-77$.

SCHMITT, Bernd H. Marketing experimental. São Paulo: Nobel, 2002.

SEVERINO, Antônio Joaquim. Metodologia do trabalho científico. 23ed. rev. e atualizada. São Paulo: Cortez, 2007. p. 99-126.

SHELTON, Ashleigh K. Defining the lines between virtual and real world purchases: Second Life sells, but who's buying? Minneapolis, 2010.

SOLOMON, Michael R. O comportamento do consumidor: comprando, possuindo e sendo. 7. ed. Porto Alegre: Bookman, 2008. 
TAURION, Cezar. Mundos Virtuais Pessoas Reais. v. 2 [S.1] 2009. p. 52-23.

TERDIMAN, Daniel. The entrepreneur's guide to Second Life: making money in the metaverse. Indianapolis: Wiley Publishing, Inc., 2008.

THILMANY, Jean. Real-Life business in Second Life. In: Mechanical Engeneering. p. 64.

TIKKANEN, Henrikki; HIETANEN, Joel; HENTTONEN, Tuomas; ROKKA, Joonas. Exploring virtual worlds: success factors in virtual world marketing. In: Manegement decision. v. 47 n. 8, 2009. Emerald Group Publishing Limited. p. 1357-1381.

VERGANI, Danielle Adria; ANDRADE, Lisandra. O Second Life como ambiente de pesquisa e teste para lançamento de produtos. In: Congrasso Brasileiro de Pesquisa e Desenvolvimento em Design, 8, 2008, São Paulo. Anais... São Paulo: AEND, 2008. p. 2491-2502.

WANDT, Holger, Opinion piece: Second Life, second identity? Journal of targeting, measurement and analysis for marketing. v. 15, n. 3. [S.1.]: Palgrave Macmillan, 2007. p. 195-197.

WOOD, Natalie T.; SOLOMON, Michael R. (Ed.). Virtual social identity and consumer behavior. Armonk: M. E. Sharpe, 2009. p. 230.

YIN, Robert K. Estudo de Caso: planejamento e métodos. 2. ed. Porto Alegre: Brookman, 2001.

\title{
CONSUMPTION EXPERIENCE IN VIRTUAL REALITIES: A CASE STUDY CONDUCTED IN SECOND LIFE
}

\begin{abstract}
This study aims at investigating how does the consumer experience in Second Life. For this, we used a qualitative case study. Data collection was developed through participant observation, dialogue inspired by ethnography and semi-structured interviews. Content analysis guided obtaining results. It was found that feelings related to the procurement process are similar to what is felt by respondents to make purchases in real life and, in some cases, are even more pleasurable.
\end{abstract}

Keywords: Second Life; Marketing; Experience consumes; Consumer behavior.

Data do recebimento do artigo: 19/02/2014

Data do aceite de publicação: 05/01/2015

Revista de Administração e Inovação, São Paulo, v.12, n.1, p.98-120, jan./mar. 2015. 